\title{
Pengaruh Profesionalisme Kerja Bidan Desa Terhadap Penyelenggaraan Program Kesehatan Ibu Dan Anak Di Wilayah Kerja Puskesmas Mapaddegat Kabupaten Kepulauan Mentawai Tahun 2020
}

\author{
Vega Octarini Br Munthe, Fatma Sylvana Dewi Harahap, Ivansri Marsaulina P \\ Ilmu Kesehatan Masyarakat, Institut Kesehatan Helvetia Helvetia \\ Email : vegaoctarini@gmail.com
}

\begin{abstract}
Abstrak
Target pencapaian program KIA di Wilayah Kerja Puskesmas Mapaddegat belum tercapai sesuai Standar Pelayanan Minimal (SPM) yaitu 100\%. Bidan desa sebagai tenaga profesional yang bertanggung jawab langsung dalam penyelenggaraan program KIA, menghadapi banyak faktor yang mempengaruhi kegiatan - kegiatan dalam program KIA. Tujuan penelitian adalah untuk mengetahui pengaruh profesionalisme kerja bidan desa terhadap penyelenggaraan program KIA di Puskesmas Mapaddegat. Desain penelitian Mixed Method Sequential Explanatory dengan metode kuantitatif pendekatan cross sectional dilanjutkan metode kualitatif. Pengambilan data menggunakan kuesioner dan wawancara. Populasi 22 orang bidan desa, tehnik pengambilan sampel adalah total sampling. Analisa data dilakukan dengan melihat distribusi frekuensi tiap variabel, uji korelasi chi-square, regresi logistik biner dan menganalisa data kualitatif. Hasil penelitian kuantitatif, variabel yang berpengaruh terhadap penyelenggaraan program KIA adalah masa kerja $P$ value 0,010 , pelatihan $P$ value 0,006 , motivasi $P$ value 0,002 , beban kerja $P$ value 0,004 , fasilitas $P$ value 0,004 , persepsi kepemimpinan $P$ value 0,019 dan kompensasi $P$ value 0,002 . Dan hasil dari analisa kualitatif, adalah motivasi yang kurang dari pimpinan berupa pemberian bimbingan dan kunjungan kerja. Kesimpulan: Variabel yang berpengaruh dominan terhadap penyelenggaraan program KIA adalah motivasi dan kompensasi. Disarankan agar pihak Dinas Kesehatan dan Puskesmas meningkatkan kemampuan dan keterampilan bidan desa melalui pelatihan pelatihan program KIA, melengkapi dan memperbaiki fasilitas kesehatan sesuai standar dan meningkatkan kesejahteraan bidan desa.
\end{abstract}

Kata kunci: Pelatihan, Motivasi, Fasilitas, Kompensasi, Bidan desa

\section{Abstract}

The target of achieving the $\mathrm{MCH}$ program in Mapaddegat Health Centre has not been achieved according to the Minimum Service Standard (SPM), which is $100 \%$. Village midwives as professionals who are directly responsible for the implementation of $\mathrm{MCH}$ program facing many factors that influence activities in $\mathrm{MCH}$ program. The study aimed to determine the effect of the work professionalism of village midwives on the implementation of $\mathrm{MCH}$ program at Mapaddegat Health Centre. The research design of Mixed Method Sequential Explanatory with quantitative methods, cross-sectional approach, followed by qualitative methods. Collecting data used questionnaires and interviews. The population was 22 village midwives and all were taken as the sample by using total sampling. Data analysis was done by looking at the frequency distribution of each variable, chi-square correlation test, binary logistic regression and analyzing qualitative data. The results of quantitative research, the variables that influence the implementation of the $\mathrm{MCH}$ program are tenure with $p$-value .010 , training with $p$-value .006 , motivation with $p$-value .002 , workload with $p$-value .004 , facilities with $p$ -

http://ejournal.urindo.ac.id/index.php/jukmas 
value .004 , perceived leadership with $p$-value .019 and compensation with $p$-value .002 . Of qualitative analysis was the leadership lacks motivation in the form of providing guidance and working visits. The conclusion showed a dominant effect on the implementation of the $\mathrm{MCH}$ program were motivation and compensation. It is suggested to the health office to improve the capacity and skills of midwives through $\mathrm{MCH}$ training programs, equip and improve health facilities according to standards and improve the welfare of midwives.

Keywords: training, motivation, facilities, compensation, village midwife

\section{PENDAHULUAN}

Masalah kesehatan Ibu dan Anak masih merupakan masalah krusial di Indonesia karena masalah tersebut merupakan salah satu indikator kesejahteraaan suatu bangsa, yang ditandai dengan masih tingginya Angka Kematian Ibu (AKI) dan Angka Kematian Bayi (AKB), dan berbagai penyakit yang dapat menyerang lbu dan Anak. Kematian ibu berdampak negatif terhadap kesejahteraan keluarga dan masyarakat serta memiliki implikasi sosial yang bermakna terhadap kualitas kesehatan keluarga di kemudian hari. Salah satu penyebabnya adalah adanya keterbatasan perempuan dalam mengakses pelayanan kesehatan, yang disebabkan oleh berbagai faktor, seperti ; kemiskinan, kondisi struktur geografis, penyebaran penduduk yang tidak merata, sosial ekonomi yang rendah, praktik budaya yang menghambat dan ketidaksetaraan gender (1).

Penilaian terhadap Kesehatan Ibu dan Anak (KIA) dapat dilihat dari pengelolaan program KIA yaitu terpantaunya cakupan dan mutu pelayanan KIA secara efektif dan efisien . Kegiatan pokok dalam pelayanan KIA adalah peningkatan pelayanan Antenatal, Persalinan oleh tenaga kesehatan yang kompeten, pelayanan nifas, pelayanan neonatus, deteksi dini faktor resiko dan penanganan komplikasi kebidanan dan neonatus, pelayanan bagi seluruh bayi dan balita, dan pelayanan KB sesuai standar . Indikator pemantauan yang digunakan untuk menggambarkan kegiatan pokok program KIA ini adalah Cakupan K4 yang menggambarkan kualitas pelayanan KIA, Cakupan Persalinan oleh tenaga kesehatan (PN) yang menggambarkan tingkat keamanan persalinan, Cakupan penanganan komplikasi kebidanan, Cakupan Kunjungan nifas dan neonatus, Cakupan penanganan Komplikasi neonatus, Cakupan kunjungan bayi, Cakupan kunjungan Balita, Cakupan pelayanan KB Aktif (8).

Profesionalisme bidan juga berarti memiliki sifat professional / ahli . Secara popular, seorang bidan dikatakan 
professional yang dimaksudkan sebagai bidan terampil atau cakap dalam kerjanya walaupun keterampilan tersebut diperoleh dari minat belajar dari kebiasaan dan dipengaruhi oleh lingkungan sosial dan lingkungan kerja (12).

Hasil dari observasi di 5 desa wilayah kerja Puskesmas Mapaddegat Kabupaten Kepulauan Mentawai, permasalahan yang paling sering dihadapi oleh bidan-bidan desa yang berhubungan dengan pelaksanaan program Kesehatan Ibu dan Anak diantaranya kemampuan dan pengalaman sebagai bidan belum maksimal, pelatihan-pelatihan tentang program KIA yang kurang, Penghargaan terhadap kinerja bidan desa yang kurang, peralatan kerja yang terbatas, beban kerja yang tidak berhubungan langsung dengan tugas pokok dan fungsi bidan, kesejahteraan bidan yang masih kurang diperhatikan oleh atasan.

Berdasarkan uraian tersebut,
peneliti tertarik untuk melakukan
penelitian yang bertujuan untuk
mengetahui dan menganalisis pengaruh
profesionalisme kinerja bidan desa dalam
penyelenggaraan program kesehatan ibu
dan anak di Puskesmas Mapaddegat
Kabupaten Kepulauan Mentawai tahun
2020, dan diharapkan dapat digunakan
sebagai bahan untuk perbaikan dan


(68,2\%), sedangkan sebagian kecil responden yang tidak pernah mengikuti pelatihan sebanyak 7 orang $(31,8 \%)$.

Hasil penelitian ini didapatkan sebagian besar responden adalah bidan desa memiliki motivasi yang tinggi sebanyak 14 orang $(63,6 \%)$, sedangkan sebagian kecil responden memiliki motivasi yang rendah sebanyak 8 orang $(36,4 \%)$. Sebagian besar responden adalah bidan desa memiliki beban kerja rendah yang sebanyak 13 orang $(59,1 \%)$, sedangkan sebagian kecil responden memiliki beban kerja yang tinggi sebanyak 9 orang $(40,9 \%)$. Sebagian responden adalah bidan desa ada dokumen SOP sebanyak 11 orang (50 \%), sedangkan sebagian responden tidak adadokumen SOP sebanyak 11 orang (50 \%). Sebagian besar responden adalah bidan desa dengan fasilitas baik sebanyak 13 orang $(59,1 \%)$, sedangkan sebagian kecil responden dengan fasilitas kurang sebanyak 9 orang $(40,9 \%)$. Hasil analisis hubungan antara usia bidan desa dengan penyelenggaraan program KIA, diperoleh bahwa ada sebanyak 12 dari $22(54,6 \%)$ bidan desa yang usianya $\geq 25$ tahun, baik dalam penyelenggaraan program KIA . Sedangkan diantara bidan desa ada 2 dari $22(9,09 \%)$ yang usianya $<25$ tahun, baik dalam penyelenggaraan program KIA . Hasil dari uji Chi-square, dengan Fisher's
Exact Test diperoleh $\mathrm{P}$ value $=0,032$ lebih kecil dari 0,05; maka hipotesis diterima ( $\mathrm{H} 1$ diterima dan HO ditolak) dan dapat disimpulkan bahwa ada hubungan yang signifikan antara usia bidan desa dengan penyelenggaraan program KIA. Hasil analisis hubungan antara masa kerja bidan desa dengan penyelenggaraan program $\mathrm{KIA}$, diperoleh bahwa ada sebanyak 11 dari 22 (50\%) bidan desa yang masa kerjanya $\geq$ 3 tahun, baik dalam penyelenggaraan program KIA . Sedangkan diantara bidan desa ada 3 dari 22 (13,6\%) yang masa kerjanya $<3$ tahun, baik dalam penyelenggaraan program KIA . Hasil dari uji Chi-square, dengan Fisher's Exact Test diperoleh $P$ value $=0,005$ lebih kecil dari 0,05; maka hipotesis diterima ( $\mathrm{H} 1$ diterima dan HO ditolak) dan dapat disimpulkan bahwa ada hubungan yang signifikan antara masa kerja bidan desa dengan penyelenggaraan program KIA .

Hasil analisis hubungan antara status kepegawaian bidan desa dengan penyelenggaraan program KIA, diperoleh bahwa ada sebanyak 10 dari 22 (45,4\%) bidan desa yang status kepegawaiannya Non PNS, baik dalam penyelenggaraan program KIA . Sedangkan diantara bidan desa ada 4 dari $22(18,2 \%)$ yang status kepegawaiannya PNS, baik dalam penyelenggaraan program KIA. Hasil dari uji Chi-square, dengan Fisher's Exact Test 
diperoleh $\mathrm{P}$ value $=0,631$ lebih besar dari 0,05; maka hipotesis ditolak (H1 ditolak dan HO diterima) dan dapat disimpulkan bahwa tidak ada hubungan antara status kepegawaian bidan desa dengan penyelenggaraan program KIA .

Hasil analisis hubungan antara
pelatihan bidan desa dengan
penyelenggaraan program $\mathrm{KIA}$, diperoleh bahwa ada sebanyak 13 dari $22(59,1 \%)$ bidan desa yang pernah mengikuti pelatihan, baik dalam penyelenggaraan program KIA . Sedangkan diantara bidan desa ada 1 dari 22 (4,5\%) yang tidak pernah mengikuti pelatihan, baik dalam penyelenggaraan program KIA. Hasil dari uji Chi-square, dengan Fisher's Exact Test diperoleh $\mathrm{P}$ value $=0,002$ lebih kecil dari 0,05; maka hipotesis diterima ( $\mathrm{H} 1$ diterima dan HO ditolak) dan dapat disimpulkan bahwa ada hubungan yang signifikan antara pelatihan bidan desa dengan penyelenggaraan program KIA .

Hasil analisis hubungan antara
motivasi bidan desa dengan penyelenggaraan program KIA, diperoleh bahwa ada sebanyak 13 dari 22 (59,1\%) bidan desa yang memiliki motivasi yang tinggi, baik dalam penyelenggaraan program KIA. Sedangkan diantara bidan desa ada 1 dari 22 (4,5\%) yang memiliki motivasi rendah, baik dalam penyelenggaraan program KIA . Hasil dari uji Chi-square, dengan Fisher's Exact Test diperoleh $\mathrm{P}$ value $=0,000$ lebih kecil dari 0,05 ; maka hipotesis diterima ( $\mathrm{H} 1$ diterima dan HO ditolak) dan dapat disimpulkan bahwa ada hubungan yang signifikan antara motivasi bidan desa dengan penyelenggaraan program KIA .

Hasil analisis hubungan antara beban kerja bidan desa dengan penyelenggaraan program $\mathrm{KIA}$, diperoleh bahwa ada sebanyak 12 dari 22 (54,6\%) bidan desa yang memiliki beban kerja yang rendah, baik dalam penyelenggaraan program KIA . Sedangkan diantara bidan desa ada 2 dari 22 (9,09\%) yang memiliki beban kerja yang tinggi, baik dalam penyelenggaraan program KIA. Hasil dari uji Chi-square, dengan Fisher's Exact Test diperoleh $P$ value $=0,001$ lebih kecil dari 0,05; maka hipotesis diterima ( $\mathrm{H} 1$ diterima dan HO ditolak) dan dapat disimpulkan bahwa ada hubungan yang signifikan antara beban kerja bidan desa dengan penyelenggaraan program KIA

Hasil analisis hubungan antara SOP dengan penyelenggaraan program $\mathrm{KIA}$, diperoleh bahwa ada sebanyak 11 dari $22(50,0 \%)$ bidan desa yang bekerja ada dokumen SOP, baik dalam penyelenggaraan program KIA. Dan ada 11 dari 22 (50\%) bidan desa yang bekerja 
tidak adadokumen SOP, baik dalam ditolak dan HO diterima) dan dapat penyelenggaraan program KIA . Hasil disimpulkan bahwa tidak ada hubungan dari uji Chi-square, dengan Fisher's Exact antara SOP dengan penyelenggaraan Test diperoleh nilai $\mathrm{P}$ value $=0,091$ lebih program KIA .

besar dari 0,05; maka hipotesis ditolak (H1

\section{Tabel 1 Variabel independen Program KIA Bidan Desa}

\begin{tabular}{|c|c|c|c|}
\hline No & Variabel & Frekuensi & $\%$ \\
\hline \multirow[t]{3}{*}{1} & Usia & & \\
\hline & $<25$ tahun & 7 & 31,8 \\
\hline & $\geq 25$ tahun & 15 & 68,2 \\
\hline \multirow[t]{3}{*}{2} & Masa Kerja & & \\
\hline & $<3$ tahun & 10 & 45,4 \\
\hline & $\geq 3$ tahun & 12 & 54,6 \\
\hline \multirow[t]{3}{*}{3} & Status Pekerjaan & & \\
\hline & Non PNS & 16 & 72,7 \\
\hline & PNS & 6 & 27,3 \\
\hline \multirow[t]{3}{*}{4} & Pelatihan & & \\
\hline & Tidak Pernah & 7 & 31,8 \\
\hline & Pernah & 15 & 68,2 \\
\hline \multirow[t]{3}{*}{5} & Motivasi & & \\
\hline & Rendah & 8 & 36,4 \\
\hline & Tinggi & 14 & 63,6 \\
\hline \multirow[t]{3}{*}{6} & Beban Kerja & & \\
\hline & Rendah & 13 & 59,1 \\
\hline & Tinggi & 9 & 40,9 \\
\hline \multirow[t]{3}{*}{7} & SOP & & \\
\hline & Tidak Ada & 11 & 50 \\
\hline & Ada & 11 & 50 \\
\hline
\end{tabular}


Tabel 2

Program KIA Bidan Desa

\begin{tabular}{cccc}
\hline No & Program KIA & Frekuensi & Persentase (\%) \\
\hline 1. & Kurang & 8 & 36,4 \\
2. & Baik & 14 & 63,6 \\
& Jumlah & Jumlah & $\mathbf{2 2}$ \\
\hline
\end{tabular}

Tabel 3 Tabel Silang Hubungan Usia, masa kerja, status kepegawaian, pelatihan, motivasi, beban kerja, SOP, fasilitas, persepsi kepemimpinan, kompensasi dan tim kerja Bidan Desa Dengan Penyelenggaraan Program KIA

\begin{tabular}{|c|c|c|c|c|c|c|c|}
\hline \multirow{3}{*}{ Variabel } & \multicolumn{4}{|c|}{ Penyelenggaraan Program KIA } & \multirow{2}{*}{\multicolumn{2}{|c|}{ Jumlah }} & \multirow{3}{*}{ Pvalue } \\
\hline & \multicolumn{2}{|c|}{ Kurang } & \multicolumn{2}{|c|}{ Baik } & & & \\
\hline & $f$ & $\%$ & f & $\%$ & $f$ & $\%$ & \\
\hline \multicolumn{8}{|l|}{ Usia } \\
\hline$<25$ tahun & 5 & 22,7 & 2 & 9,09 & 7 & 31,8 & \\
\hline$\geq 25$ tahun & 3 & 13,6 & 12 & 54,6 & 15 & 68,2 & 0,032 \\
\hline Masa Kerja & 7 & 31,8 & 3 & 13,6 & 10 & 45,4 & 0,005 \\
\hline$<3$ tahun & 1 & 4,5 & 11 & 50 & 12 & 54,6 & \\
\hline \multicolumn{8}{|l|}{$\geq 3$ tahun } \\
\hline \multicolumn{8}{|l|}{ Status } \\
\hline \multicolumn{8}{|l|}{ Kepegawaian } \\
\hline Non PNS & 6 & 27,3 & 10 & 45,4 & 16 & 72,7 & 0,631 \\
\hline PNS & 2 & 9,09 & 4 & 18,2 & 6 & 27,2 & \\
\hline \multicolumn{8}{|l|}{ Pelatihan } \\
\hline Tidak Pernah & 6 & 27,3 & 1 & 4,5 & 7 & 31,8 & \\
\hline Pernah & 2 & 9,09 & 13 & 59,1 & 15 & 68,2 & 0,002 \\
\hline \multicolumn{8}{|l|}{ Motivasi } \\
\hline Rendah & 7 & 31,8 & 1 & 4,5 & 8 & 36,4 & 0,000 \\
\hline Tinggi & 1 & 4,5 & 13 & 59,1 & 14 & 63,6 & \\
\hline
\end{tabular}


Beban Kerja

$\begin{array}{cccccccc}\text { Rendah } & 1 & 4,5 & 12 & 54,6 & 13 & 59,1 & 0,001 \\ \text { Tinggi } & 7 & 31,8 & 2 & 9,09 & 9 & 40,9 & \end{array}$

SOP

$\begin{array}{clllllll}\text { Tidak Ada } & 6 & 27,3 & 5 & 22,7 & 11 & 50 & 0,091 \\ \text { Ada } & 2 & 9,09 & 9 & 40,9 & 11 & 50 & \end{array}$

PEMBAHASAN

Hasil dari uji Chi-square, $\overline{\text { dengan }}$

Bahwa sebagian besar Fisher's Exact Test diperoleh $\mathrm{P}$ value $=$ 0,032 lebih kecil dari 0,05; maka responden adalah bidan desa yang berusia $\geq 25$ tahun sebanyak 15 orang $(68,2 \%)$, sedangkan sebagian kecil responden berusia $<25$ tahun sebanyak 7 orang $(31,8 \%)$. Hal ini menggambarkan bahwa bidan desa di wilayah kerja Puskesmas Mapaddegat rata-rata dalam usia produktif untuk bekerja dan potensial diberdayakan untuk meningkatkan kinerja dalam penyelenggaraan program KIA . Hasil penelitian ini sejalan dengan penelitian yang dilakukan oleh Nisa. K (2019) yang menyatakan bahwa usia bidan di wilayah kerja puskesmas kota Bukittinggi lebih dari separuh $(50,7 \%)$ adalah usia produktif dimana pada usia ini mereka memiliki inovasi lebih beragam dalam hal pemecahan masalah dan sebagian besar bidan juga kompeten dalam memberikan pelayanan (15) . disimpulkan bahwa ada hubungan yang signifikan antara usia bidan desa dengan penyelenggaraan program KIA . Hal ini tidak sejalan dengan penelitian Hidayat. $\mathrm{M}$, dkk (2018) bahwa variabel usia memperoleh $P$-value sebesar 0,132 berarti tidak ada hubungan bermakna dengan kualitas pelayanan persalinan. Usia merupakan ciri dari kedewasaan fisik dan kematangan kepribadian yang erat hubungannya dengan pengambilan keputusan, mulai usia 21 tahun secara hukum dikatakan mulai masa dewasa dan pada 30 tahun telah mampu menyelesaikan masalah dengan cukup baik, menjadi stabil dan tenang secara emosional . Bertambahnya usia seseorang akan terjadi perubahan pada aspek fisik dan psikologi. Sehingga apabila semakin dewasa seseorang, maka akan semakin mudah dalam menerima 
informasi, maka pemikirannya akan semakin berkembang bertambah baik dalam memberikan pelayanan KIA (49).

Dari hasil analisis multivariat, diperoleh nilai probabilitas sebesar 0,085 yang lebih besar dari 0,05, maka disimpulkan bahwa usia tidak berpengaruh terhadap penyelenggaraan program KIA di wilayah kerja Puskesmas Mapaddegat .

Hasil Penelitian menunjukkan sebagian besar responden adalah yang mempunyai masa kerja $\geq 3$ tahun sebanyak 12 orang (54,6\%), sedangkan sebagian kecil responden mempunyai masa kerja $<3$ tahun sebanyak 10 orang $(45,4 \%)$. Hal ini menunjukkan bahwa bidan desa di wilayah kerja Puskesmas Mapaddegat sebagian besar telah mempunyai pengalaman yang lebih dari cukup dalam penyelenggaraan program KIA, sudah cukup memahami situasi masyarakat, mendapat kepercayaan dari masyarakat dan dapat menyelesaikan masalah-masalah yang dihadapi . Sesuai dengan salah satu fungsi bidan desa adalah meningkatkan pelayanan KIA sehingga dituntut untuk dapat menggerakkan masyarakat agar ikut berpartisipasi dalam kesehatan dengan cara bersosialisasi dengan masyarakat tempat dimana mereka bertugas. Sejalan dengan penelitian yang dilakukan oleh Fatrin. T (2017), menyatakan bahwa $62,5 \%$ bidan di RS
Muhammadiyah Palembang mempunyai masa kerja $>3$ tahun dimana bidan yang masa kerjanya $>3$ tahun telah mempunyai pengalaman dalam bekerja, dimana pengalaman merupakan suatu cara untuk memperoleh pengetahuan yang dilakukan dengan cara mengulang kembali pengalaman yang diperoleh dalam memecahkan masalah yang dihadapai di masa lalu . Dan bidan yang masa kerjanya $<3$ tahun masih belum terampil, masalah ini dapat diatasi dengan berjalannya waktu dan selama itu pula bidan memperoleh banyak pengalaman dan pelajaran yang dijumpai sehingga dapat memberikan pelayanan efektif dan efisien serta mahir dalam pelayanan (49).

Hasil dari uji Chi-square, dengan Fisher's Exact Test diperoleh $P$ value $=$ 0,005 lebih kecil dari 0,05; maka disimpulkan bahwa ada hubungan yang signifikan antara masa kerja bidan desa dengan penyelenggaraan program KIA . Sejalan dengan penelitian Nasir. M, dkk (2017), Masa kerja memberikan pengaruh positif pada kinerja seseorang, dengan semakin lama masa kerja seseorang maka akan semakin berpengalaman dalam melaksanakan tugasnya . Lamanya bidan bekerja dapat diidentikkan dengan banyaknya pengalaman yang dimilikinya . Hal ini dikarenakan semakin lama bidan bekerja maka kinerjanya akan semakin 
baik . Diharapkan dengan semakin lama bidan bekerja maka bidan semakin berpengalaman sehingga bidan mampu memberikan bentuk pelayanan yang terbaik, semakin lama seseorang bekerja pada suatu organisasi maka semakin berpengalaman orang tersebut sehingga kecakapan kerjanya semakin baik. Oleh sebab itu, bidan yang telah lama bekerja diharapkan memiliki kemampuan lebih baik dalam memberikan pelayanan KIA (10).

Dari hasil analisis multivariat, diperoleh nilai probabilitas dari masa kerja adalah sebesar 0,010 yang lebih kecil dari 0,05 , yang menunjukkan bahwa masa kerja berpengaruh signifikan terhadap penyelenggaraan program KIA .

Hasil penelitian menunjukkan bahwa sebagian besar responden adalah bidan desa yang memiliki status kepegawaian Non PNS sebesar $72,7 \%$, dan $27,7 \%$ yang memiliki status kepegawaian PNS . Berdasarkan data ini dapat dilihat bahwa lebih dari separuh bidan desa di wilayah kerja Puskesmas Mapaddegat dengan status kepegawaiannya adalah Non PNS yang memiliki perjanjian kerja dengan dinas kesehatan Kabupaten Kepulauan Mentawai yang diperbaharui setiap tahun. Hasil penelitian ini berbanding terbalik dengan penelitian Zukfatunnis.N, dkk (2016) yang menunjukkan bahwa responden yang berstatus sebagai Pegawai Tidak Tetap (PTT) sebesar 29,3\% dan responden sebagai Pegawai Negeri Sipil (PNS) 70,7\% . Hal ini menunjukkan bahwa jumlah dan kebutuhan bidan desa di setiap daerah berbeda-beda (27).

Hasil dari uji Chi-square, dengan Fisher's Exact Test diperoleh $P$ value $=$ 0,631 lebih besar dari 0,05 ; maka disimpulkan bahwa tidak ada hubungan antara status kepegawaian bidan desa dengan penyelenggaraan program KIA . Sejalan dengan penelitian Zulfatinnus. N, dkk (2016) dari hasil uji Chi-Square diperoleh $p$-value sebesar 0,158>0,05 berarti menunjukkan tidak ada hubungan yang signifikan antara status kepegawaian dengan dalam pemantauan persalinan . Status kepegawaian bidan merupakan keadaan/kedudukan bidan dalam hubungannya dengan lingkungan/tempat kerja, dimana bidan merupakan salah satu pendorong seseorang melakukan perbuatan atau tindakan tertentu sesuai dengan kewenangan dan tanggung jawabnya (27).

Hasil penelitian menunjukkan bahwa sebagian besar responden adalah bidan desa yang tidak pernah mengikuti pelatihan program KIA sebesar 31,8\%, dan $68,2 \%$ yang pernah mengikuti pelatihan. Hal ini sejalan dengan penelitian Nisa. K, 
dkk (2018), dengan hasil yang didapatkan lebih dari separuh bidan di puskesmas Kota Bukittinggi belum pernah mengikuti pelatihan sebesar $67,2 \%$. Pelatihan merupakan salah satu cara untuk mengembangkan sumber daya manusia yang tujuannya adalah meningkatkan kemampuan dan keterampilan kerja seseorang (15).

Hasil dari uji Chi-square, dengan Fisher's Exact Test diperoleh $\mathrm{P}$ value = 0,002 lebih kecil dari 0,05; maka disimpulkan bahwa ada hubungan yang signifikan antara pelatihan bidan desa dengan penyelenggaraan program KIA. Pelatihan lebih merujuk pada pengembangan keterampilan bekerja yang dapat digunakan dengan segera pelatihan untuk meningkatkan ketrampilan seorang karyawan agar kinerjanya meningkat. Hasil penelitian ini diperkuat oleh pendapat menurut Hasibuan (2014). Karyawan semakin ahli dan terampil dalam melaksanakan pekerjaannya. Penelitian ini sejalan dengan penelitian yang dilakukan oleh Mindarsih (2019), Pelatihan APN yang optimal dapat meningkatkan pengetahuan dan keterampilan bidan. Indikator Efektivitas pelatihan Untuk meningkatkan kualitas pembelajaran, maka indikator efektivitas pelatihan dapat dilihat dari beberapa indikator (Hasibuan, 2014) :1) Tambahan pengetahuan atau kemampuan peserta atau wawasan, 2) Kemampuan peserta mengingat isi pelatihan atau kemampuan, 3) Kemampuan peserta mempraktikan materi pelatihan atau trampil (32).

Hasil dari analisis multivariat, diperoleh nilai probabilitas dari pelatihan adalah sebesar 0,006 yang lebih kecil dari 0,05 , yang menunjukkan bahwa pelatihan berpengaruh signifikan terhadap penyelenggaraan program KIA.

Hasil penelitian menunjukkan bahwa sebagian besar responden adalah bidan desa memiliki motivasi yang tinggi sebesar $63,6 \%$, dan $36,4 \%$ yang memiliki motivasi yang rendah. Sejalan denga penelitian Sari (2017), menunjukkan bahwa kinerja bidan yang baik dengan proporsi motivasi baik lebih besar daripada yang motivasinya tidak baik dalam melaksanakan program kelas ibu hamil (50).

Hasil dari uji Chi-square, dengan Fisher's Exact Test diperoleh $\mathrm{P}$ value $=$ 0,000 lebih kecil dari 0,05; maka disimpulkan bahwa ada hubungan yang signifikan antara motivasi bidan desa dengan penyelenggaraan program KIA. Motivasi adalah berasal dari kata latin "Movere" yang berarti "dorongan atau daya penggerak", khususnya kepada para bawahan atau pengikut atau suatu 
keadaan dari dalam diri sendiri yang memberi kekuatan, yang menggiatkan, atau yang menggerakkan, dan sebagai suatu proses yang menjelaskan intensitas, arah dan ketekunan seorang individu untuk mencapai tujuannya. Salah satu tujuan pemberian motivasi adalah mendorong gairah dan semangat kerja pada karyawan.

Sejalan dengan penelitian Kusyanti. F (2017), yang menyatakan ada hubungan yang bermakna antara motivasi dengan kinerja bidan dalam pemantauan pencatatan dan pelaporan posyandu, motivasi bidan kurang disebabkan oleh kurangnya prasarana dalam membuat pencatatan dan pelaporan. Sejalan dengan hasil penelitian Nisa. K, dkk (2019) sebagian besar responden sudah memiliki motivasi yang baik. Responden mengatakan bahwa banyak faktor yang saling berkaitan yang dapat meningkatkan motivasi dari bidan, salah satunya adalah peran dari pimpinan dan suasana bekerja yang nyaman. Selain itu bidan juga mendapatkan reward dan penghargaan dengan adanya tunjangan tambahan penghasilan .

Nilai probabilitas dari motivasi adalah sebesar 0,002 yang lebih kecil dari 0,05 , yang menunjukkan bahwa motivasi berpengaruh signifikan terhadap penyelenggaraan program KIA .
Motivasi dari diri sendiri (motivasi intrinsik) dapat mempengaruhi pekerjaan salah satunya peluang untuk maju . Dalam hal ini bidan desa termotivasi untuk tetap bekerja menjadi bidan desa adalah berharap menjadi Pegawai Negeri Sipil (PNS) . Adanya kebijakan pemerintah tentang pengangkatan tenaga honorer menjadi PNS memberi semangat kepada bidan desa dan berharap suatu saat akan diangkat menjadi PNS, sehingga bidan-bidan desa di wilayah kerja puskesmas Mapaddegat masih bersedia mengabdikan diri dengan bekerja sebagai tenaga honorer (Non PNS) yang di tempatkan di pustu / poskesdes / polindes .

Hasil penelitian menunjukkan bahwa sebagian besar responden memiliki beban kerja yang tinggi 40,9\%, dan 59,1\% memiliki beban kerja yang rendah . Beban kerja bidan desa di wilayah kerja Puskesmas Mapaddegat tidak hanya melaksanakan program KIA tetapi mencakup semua program puskesmas dalam lingkup satu desa dan dengan waktu penuh 24 jam melayani. Berdasarkan Peraturan Menteri dalam Negeri Nomor 12 tahun 2008, tentang pedoman analisis beban kerja di lingkungan departemen dalam negeri, untuk jam formal adalah 37,5 jam per minggu. Hal ini sejalan dengan penelitian Marsaoly. S (2019) dapat 
dilihat bahwa bidan yang bekerja di Puskesmas Sulamadaha memiliki beban kerja berat sebanyak 36 orang (100\%) . Apabila para pekerja merasa beban kerja yang harus ditanggung terasa semakin berat, itu berarti pekerjaan yang ditugaskan kepada mereka tidak sesuai dengan kemampuan untuk menyelesaikan tugas tersebut (51).

Hasil dari uji Chi-square, dengan Fisher's Exact Test diperoleh $\mathrm{P}$ value $=$ 0,001 lebih kecil dari 0,05; maka dapat disimpulkan bahwa ada hubungan yang signifikan antara beban kerja bidan desa dengan penyelenggaraan program KIA . Beban kerja merupakan sejauh mana kapasitas individu pekerja dibutuhkan dalam menyelesaikan tugas yang diberikan kepadanya, yang dapat diindikasikan dari jumlah pekerjaan yang harus dilakukan, waktu / batasan waktu yang dimiliki oleh pekerja dalam menyelesaikan tugasnya, serta pandangan subjektif individu tersebut sendiri mengenai pekerjaan yang diberikan kepadanya (52).

Dalam penelitian Santi. M (2016), meskipun secara statistik disimpulkan bahwa tidak ada hubungan antara beban kerja dengan kinerja tetapi ditemukan bahwa sebagian besar bidan yang merasakan beban kerja dengan tingkat sedang mempunyai kinerja yang kurang baik dan sebaliknya pada bidan konselor ASI yang merasakan beban kerja ringan justru mayoritas berkinerja baik . Hal ini dapat terjadi dikarenakan beban kerja dapat mempengaruhi stress kerja yang pada akhirnya akan berdampak pada rendahnya kinerja, bahwa apabila beban kerja yang diterima terlalu besar maka akan dapat menimbulkan stress kerja yang bisa mempengaruhi motivasi kerja dan menurunnya kinerja . Menurunnya motivasi akan menyebabkan menurunnya kinerja .

Nilai probabilitas dari beban kerja adalah sebesar 0,004 yang lebih kecil dari 0,05 , yang menunjukkan bahwa beban kerja berpengaruh signifikan terhadap penyelenggaraan program KIA .

Hasil penelitian menunjukkan bahwa sebagian besar responden adalah bidan desa ada dokumen SOP sebesar 50\% dan $50 \%$ yang tidak ada dokumen SOP . Berdasarkan hasil penelitian Abu.H, dkk (2015) didapatkan pelaksanaan pelayanan sesuai SOP pelayanan antenatal care sebanyak (67\%) yang dikategorikan cukup baik (17).

Hasil dari uji Chi-square, dengan Fisher's Exact Test diperoleh nilai $\mathrm{P}$ value $=$ 0,091 lebih besar dari 0,05; maka dapat disimpulkan bahwa tidak ada hubungan antara SOP dengan penyelenggaraan 
program KIA. Hal ini sejalan dengan penelitian Rosmadewi (2019) yang menunjukkan bahwa hasil uji statistik diperoleh nilai $p$-value $=0,846$, maka berarti secara statistik tidak ada hubungan antara tingkat kepatuhan bidan dan dalam penerapan SOP pemotongan tali pusat (53).

\section{SIMPULAN}

Variabel yang berpengaruh dominan terhadap penyelenggaraan program KIA adalah motivasi dan kompensasi .

\section{SARAN}

Disarankan agar pihak Dinas Kesehatan dan Puskesmas meningkatkan kemampuan dan keterampilan bidan desa melalui pelatihan - pelatihan program KIA, melengkapi dan memperbaiki fasilitas kesehatan sesuai standar dan meningkatkan kesejahteraan bidan desa .

\section{DAFTAR PUSTAKA}

1. IBI. Buku Acuan Midwifery Update. Jakarta: Pengurus Pusat IBI; 2016.

2. List of countries by maternal mortality ratio. 2015;

3. Kemenkes RI. Profil Kesehatan Indonesia 2018. 2019.

4. Zannah AN. Motivation, Persuasive Communication, And Obstetric Risk
Management Training To Improve

Midwives Professionalism In Preventing Maternal Death. J Kesehat dr Soebandi. 2018;6(2):9-16 .

5. Dinas Kesehatan Propinsi Sumatera Barat. Profil Kesehatan Sumatera Barat 2018. 2019.

6. Dinas Kesehatan Kabupaten Kepulauan Mentawai. Profil Kesehatan Kabupaten Kepulauan Mentawai 2018. 2019.

7. UNICEF. Maternal and Newborn Health Disparities. 2018;

8. Kemenkes RI. Pedoman Pemantauan Wilayah Setempat Kesehatan Ibu dan Anak (PWS-KIA). Jakarta; 2010 .

9. Zulvadi D. Etika dan Manajemen Kebidanan. Yogyakarta: Jaya IImu; 2014.

10. Nasir M. Faktor Yang Mempengaruhi Kinerja Bidan Desa Dalam Meningkatkan Pelayanan Antenatal Care Di Puskesmas Kabupaten Halmahera Tengah. 2017;2(3):28390 .

11. Depkes RI. Pedoman Bidan Koordinator. Jakarta; 2010.

12. Safarudin. Pengembangan Kepribadian dan Profesionalisme Bidan. Wineka Media; 2018.

13. Farida E. Analisis Pengaruh Pelatihan, Motivasi dan Lingkungan Kerja Terhadap Kinerja Bidan Yang 
Berdampak Pada Kepuasan Kerja Di Kabupaten Bangka Barat. J JEM. 2019;vol 5(no.1):42-63 .

14. Danardono SI, Pribadi F. Kepuasan dan Motivasi Tenaga Medis: Studi Kasus Terhadap Pendapatan , Kompensasi dan Lingkungan Kerja Pada Rumah Sakit. 2016;5(1):63-72 .

15. Nisa K. Analisis Faktor yang Berhubungan dengan Kinerja Bidan dalam Memberikan Pelayanan Antenatal Berkualitas Diwilayah Kerja Puskesmas Kota Bukittinggi Tahun 2018. J Ilm Univ Batanghari Jambi. 2019;19(1):53-60 .

16. Melati K. Analisis Beban Kerja Bidan Desa Di Puskesmas Duren Kabupaten Semarang. JKM FKM UNDIP. 2015;3(April):30-40 .

17. Abu A. Hubungan Karakteristik Bidan Dengan Mutu Pelayanan Antenatal Care Berdasarkan Standar Operasional. JKMA. 2015;10(no.1):94102.

18. Sumiati L. Pengaruh Penerapan Prosedur Kerja Terhadap Peningkatan Kinerja Bidan Desa Dalam Pelayanan Kebidanan Di Kabupaten Sukabumi. J IJEMC. 2014;1(no 1):32-40 .

19. Adiputri A. Kompetensi, Kompensasi Finansial, Supervisi dan Kinerja Bidan Desa di Kabupaten Bangli The Competency, Financial Compensation
, Supervision and Performance of the Village Midwives in the Bangli Regency Pendahuluan Metode Desain penelitian adalah survei. Public Heal Prev Mecine Arch. 2014;2(no.1):96101.

20. Nita E. Faktor - faktor Berhubungan Dengan Kinerja Bidan Desa Di Wilayah Puskesmas Kasimbar Parigi Mautong. J Kesehat Masy Andalas. 2015;10(no.1):94-100.

21. Hasibuan A. Etika Profesi dan Profesionalisme Kerja. Medan: UISU Press; 2017.

22. Masram. Manajemen Sumber Daya Manusia Profesional. Sidoarjo: Zifatama Publisher; 2017 .

23. Purwoastuti TE. Etikolegal Dalam Praktik Kebidanan. Yogyakarta: Pustaka Baru Press; 2015

24. Muchtar M. Etika Profesi dan Hukum Kesehatan. Yogyakarta: Pustaka Baru Press; 2015 .

25. Kemenkes RI. Peraturan Menteri Kesehatan No. 43 Tahun 2019 Tentang Puskesmas. In 2019 .

26. Sholichah A. Teori - teori Pendidikan Dalam Al-qur'an. J Edukasi Islam. 2018;7(no 1):23-46.

27. Zulfatunnis N. Hubungan Pelatihan APN dan Status Kepegawaian Dengan Keterampilan Partograf dalam 
Jurnal Untuk Masyarakat Sehat (JUKMAS)

pemantauan persalinan. J PROFESI.

2016;14(September):56-61.

28. Adriansyah A. Pengaruh Usia dan Lama Kerja Bidan terhadap Kesadaran Sosial Bidan Dalam Pemberian Tablet Fe Pada Ibu Hamil. J IKESMAS. 2017;13(no.1):94-102. 